\title{
Article \\ Electrosynthesis of HKUST-1 with Flow-Reactor Post-Processing
}

\author{
Mikko Vepsäläinen ${ }^{1, *}$, David S. Macedo ${ }^{1}\left(\mathbb{0}\right.$, Huan Gong ${ }^{1}$, Marta Rubio-Martinez ${ }^{1}$, Bita Bayatsarmadi ${ }^{1}$ \\ and Brandon $\mathrm{He}^{2}$ \\ 1 CSIRO Mineral Resources, Private Bag 10, Clayton South, VIC 3169, Australia; \\ david.macedo@csiro.au (D.S.M.); huan.gong@csiro.au (H.G.); martonarubio@gmail.com (M.R.-M.); \\ bita.bayatsarmadi@csiro.au (B.B.) \\ 2 CSIRO Manufacturing, Private Bag 10, Clayton South, VIC 3169, Australia; Brandon.He1@monash.edu \\ * Correspondence: mikko.vepsalainen@vtt.fi
}

check for updates

Citation: Vepsäläinen, M.; Macedo, D.S.; Gong, H.; Rubio-Martinez, M.; Bayatsarmadi, B.; He, B.

Electrosynthesis of HKUST-1 with Flow-Reactor Post-Processing. Appl. Sci. 2021, 11, 3340. https://doi.org/ 10.3390/app11083340

Academic Editor: Jenny Vitillo

Received: 24 February 2021

Accepted: 30 March 2021

Published: 8 April 2021

Publisher's Note: MDPI stays neutral with regard to jurisdictional claims in published maps and institutional affiliations.

Copyright: (c) 2021 by the authors. Licensee MDPI, Basel, Switzerland. This article is an open access article distributed under the terms and conditions of the Creative Commons Attribution (CC BY) license (https:// creativecommons.org/licenses/by/ $4.0 /)$.

\begin{abstract}
Electrochemical synthesis has been proposed as an efficient method for cost-effective and large-scale production of metal-organic frameworks (MOFs). This work investigates the combined electrochemical synthesis with flow synthesis post-treatment for the production of high surface area HKUST-1. The electrochemical synthesis process used in the experimental work did not require additional electrolytes or washing of the synthesis product. Batch electrosynthesis and electrosynthesis with flow synthesis were compared for the quality of the product using Brunauer-Emmett-Teller (BET) surface area, X-ray diffraction (XRD), and scanning electron microscopy (EIS). Batch electrosynthesis in $0.01 \mathrm{M}$ benzene-1,3,5-tricarboxylic acid ( $\mathrm{H}_{3} \mathrm{BTC}$ ) solution produced HKUST-1 with BET surface area of $1550 \mathrm{~m}^{2} / \mathrm{g}$ which was increased further to $1716 \mathrm{~m}^{2} / \mathrm{g}$ with post-flow-synthesis treatment. The greatest change in surface area after flow processing was observed when using $0.78 \mathrm{M}$ $\mathrm{H}_{3}$ BTC, with corresponding surface areas of $481 \mathrm{~m}^{2} / \mathrm{g}$ and $1531 \mathrm{~m}^{2} / \mathrm{g}$. According to SEM and BET results, the product purity improved during the post-flow-synthesis treatment. The proposed method enables continuous flow synthesis of high-quality MOFs with minimal purification steps.
\end{abstract}

Keywords: metal-organic framework; electrosynthesis; flow synthesis; HKUST-1

\section{Introduction}

Metal-organic frameworks (MOFs) are crystalline materials comprised of metal ions connected via coordination bonds with organic linkers. The diversity of metal ions and organic linkers available for use as building blocks have resulted in the creation of thousands of MOFs with a broad range of characteristics. In particular, the high surface area of certain MOFs has encouraged research in gas adsorption and fuel storage applications [1,2]. Despite a large number of reported MOFs very few have been successfully commercialised, due in part to the small scales of most synthetic methods [3]. It is beyond the scope of this work to present a comprehensive summary of MOFs synthesis methods and the reader is directed towards the existing review papers [4-8].

Recent work has demonstrated that continuous flow synthesis is a promising method for increasing the scale of MOFs production while maintaining product quality [9,10]. In comparison to a typical reaction vessel, continuous flow reactors offer a higher ratio of surface area to volume and the enhanced scalability of this ratio is beneficial for improving synthetic yields. Parameters such as reactor temperature, flow rate, and retention time can be adjusted to customise the properties of the desired MOFs. Other advantages of this methodology include its efficient heat and mass transfer; relatively fast synthesis time; and modularity, allowing for the incorporation of additional treatments or analysis. However, as metal salts are usually used as starting materials the metal's counter-ion can form various waste products which must be disposed of, and on large scales, it can take days to wash this waste off the product. 
In 2005 BASF patented an electrochemical method for MOFs synthesis which uses electrodes as a source of metal ions [11]. Anodic dissolution works by electrochemically oxidising an electrode made of the desired metal as it is submerged in a solution containing the other reactants [5]. As metal salts can be avoided this method is cleaner than other techniques; however, adding an electrolyte is typically required to improve the conductivity of the solution [12,13]. Reaction conditions such as current density, electrolyte, and solution conductivity offer additional forms of control over other synthetic techniques. In addition to bulk synthesis, this method can also be used to prepare MOFs layers on conductive substrates [14]. Electrochemical synthesis is faster than solvothermal and slow diffusion methods, requires less solvent, and can be operated continuously; however, to date, only a small number of MOFs have been electrochemically synthesised. Prevention of electrode passivation is a challenge when performing electrosynthesis on long time scales, however, this can be resolved by intermittent polarity reversal of the electrodes [15].

HKUST-1, or $\left[\mathrm{Cu}^{\mathrm{II}_{3}}(\mathrm{BTC})_{2}\right.$ ] where $\mathrm{H}_{3} \mathrm{BTC}$ = benzene-1,3,5-tricarboxylic acid, was first reported in 1999 [16]. Originally synthesised solvothermally, HKUST-1 has since been widely studied for its gas adsorption qualities [2], and potential applications in separations and heterogeneous catalysis $[17,18]$. HKUST-1 has now been synthesised using a range of methodologies including mechanochemically [19], continuous flow [10,20], and electrochemically [16]; the latter of these methods being used in the production of commercial HKUST-1 known as BasoliteTM C300. This paper is the first published research where the combination of electrochemical MOFs synthesis with continuous flow chemistry is investigated. The research aims to produce a scalable synthesis method that produces high-quality MOFs without additional electrolyte or washing.

\section{Materials and Methods}

\subsection{Synthesis Procedure}

A schematic figure of the test system is shown in Figure 1. Copper plates $(>99.9 \%$ purity, Goodfellow) with dimensions of $25 \mathrm{~mm}, 100 \mathrm{~mm}$, and $1 \mathrm{~mm}$ were separated using PVC spacers and screws. Benzene-1,3,5-tricarboxylic acid $\left(\mathrm{H}_{3} \mathrm{BTC}\right)$, was dissolved in an ethanol and water mixture (50:50 volume ratio). No additional electrolyte was used. The set-up was current-controlled with varying voltage. A laboratory potentiostat Autolab PGSTAT $302 \mathrm{~N}$ was used as a programmable power supply throughout the experiments which enabled programming of polarity reversal frequency.

Batch electrosynthesis

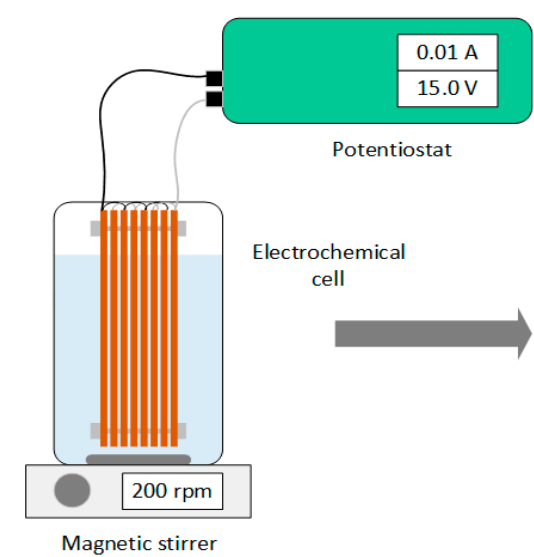

Flow processing

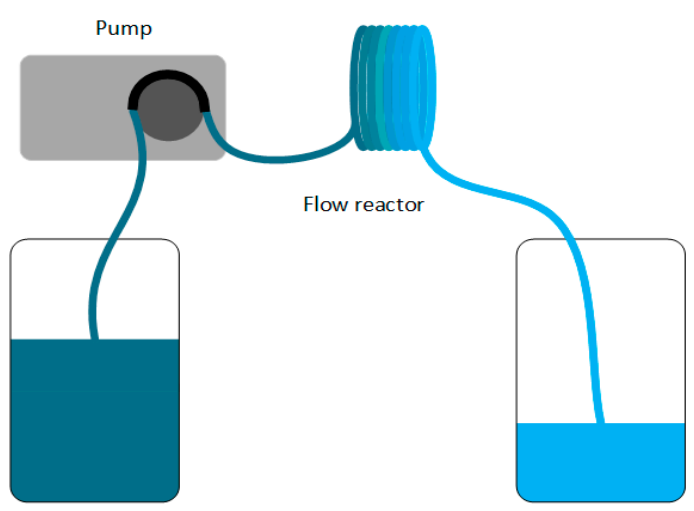

Figure 1. A schematic illustration of the test system including batch electrosynthesis and post-processing with a flow reactor.

Post-treatment was done using a Vapourtec R4 flow reactor with three $10 \mathrm{~mL}$ reactor coils. The solution from the electrochemical synthesis was passed through the reactor using a peristaltic pump. The experimental conditions during the flow-processing were; 
temperature $80^{\circ} \mathrm{C}, 6 \mathrm{~min}$ residence time and ligand concentration from $0.01 \mathrm{M}$ to $0.10 \mathrm{M}$. For gravimetric analysis samples were collected from the reactor vessel during the operation and vacuum filtered using a membrane with $0.45 \mu \mathrm{m}$ pore size. Once dry the product was heated to $120^{\circ} \mathrm{C}$ for $2 \mathrm{~h}$ to evaporate any remaining solvent from the MOFs pores. After this time the product was cooled in a vacuum desiccator then quickly weighed to measure the dry mass.

\subsection{Characterisation}

SEM images were created with secondary electrons (SE) and backscattered electrons (BSE) using a Quanta 400 field emission gun environmental scanning electron microscope, manufactured by FEI Company (Hillsboro, OR, USA). Samples were coated with a $10 \mathrm{~nm}$ thick layer of carbon to dissipate the charge, using an Auto 306 model vacuum coater manufactured by Edwards (Burgess Hill, UK). The electron gun in the SEM is a Schottkytype field emission gun. SE imaging was performed using the Everhart-Thornly detector, and BSE imaging was performed using a silicon PIN diode solid-state detector.

Powder X-ray diffraction (PXRD) measurements were performed using a Bruker D8 Advance Series 1 diffractometer. The diffractometer was equipped with a LynxEye detector and the divergence slit was set to $0.2 \mathrm{~mm}$. Samples were scanned over the $2 \theta$ range $5^{\circ}$ to $85^{\circ}$ with a step size of $0.02^{\circ}$ and a count time of 1.6 s per step. $178 / 192$ of the sensor strips on the LynxEye detector were used. A simulated HKUST-1 pattern was created using Mercury software and a Crystallographic Information File (reference code FIQCEN) from the Cambridge Structural Database.

For gas sorption measurements, HKUST-1 was evacuated and activated under dynamic vacuum at $10-6$ Torr at $140{ }^{\circ} \mathrm{C}$ for $24 \mathrm{~h}$. Ultra-high purity N2 gas (99.99\%) was used for the experiments. N2 adsorption and desorption measurements were conducted at $77 \mathrm{~K}$. Surface area measurements were performed on $\mathrm{N} 2$ isotherms at $77 \mathrm{~K}$ using the Brunauer-Emmett-Teller (BET) model with adsorption values increasing range of $0.01-0.9$ relative pressures.

\section{Results and Discussion}

\subsection{Anodic Dissolution of Copper during Electrosynthesis}

The theory of anodic dissolution of copper has been well established in corrosion literature [21,22]. Copper can dissolve via one-electron and two-electron mechanisms. In aqueous solutions, a cuprous oxide $\left(\mathrm{Cu}_{2} \mathrm{O}\right)$ layer is typically formed on the electrode passivating the surface; however, the high current densities typically used in MOFs electrosynthesis processes will make the surface trans-passive. In the trans-passive region, the corrosion current is increased and a more soluble cupric oxide $(\mathrm{CuO})$ is formed. The highly oxidizing environment of the trans-passive region constantly generates oxides and corrosion products that are released into the solution.

Typically, the interelectrode distance of the anode and cathode has not been reported for the HKUST-1 electrosynthesis studies [12,23]. Additional electrolytes, such as tetrabutylammonium tetrafluoroborate or tributylammonium methyl sulfate, are usually required to enhance the conductivity of the solution, and this electrolyte needs to be removed from the product in the subsequent washing stages. In this research, an interelectrode distance of $0.5 \mathrm{~mm}$ was used without any additional electrolytes. A short electrolyte path between the electrodes reduced the cell voltage but the system was more prone to blocking and short-circuiting (Figure 2a). Electrosynthesis with direct current (DC) resulted in HKUST-1 crystal growth on the electrode surfaces. Anode surfaces were covered with blue precipitate, indicating HKUST-1 formation, whereas cathode plates were covered with dark precipitate. Passive layers that formed on the electrode surfaces inhibited the current flow and increased the cell voltage, eventually leading to blocking or short-circuiting of the cell. A similar short-circuit phenomenon was detected in a smaller electrochemical test cell in our earlier research where XRD analysis indicated that small copper particles 
were deposited onto the cathode, eventually creating a conductive pathway between the electrodes [15].

(a)

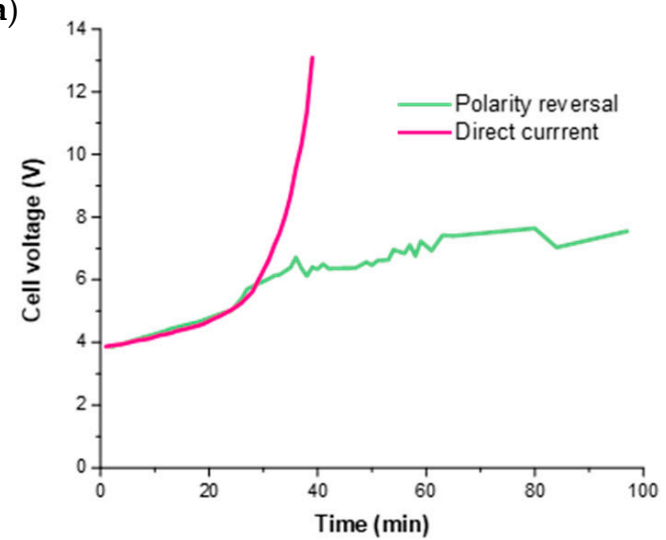

(b)

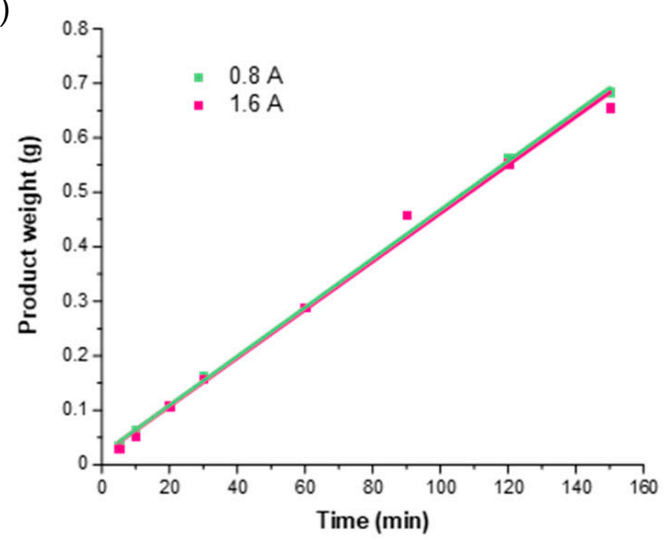

Figure 2. (a) The cell voltage of the electrosynthesis system with and without $0.250 \mathrm{~Hz}$ polarity reversal frequency with $0.8 \mathrm{~A}$ current, and (b) the product in the solution when synthesis was done using $0.8 \mathrm{~A}$ and $1.6 \mathrm{~A}$ currents with $0.250 \mathrm{~Hz}$ polarity reversal frequency. The syntheses were done at ambient temperature in $0.078 \mathrm{M}$ BTC solution.

A study on the formation of HKUST-1 on copper surfaces identified four stages in the process: initial nucleation, growth of the island, intergrowth, and detachment [24]. At low current densities, the nucleation does not take place on the electrode surface but rather in the solution because the nucleation threshold on the surface is not reached. In this research, we used two currents of $0.8 \mathrm{~A}$ and 1.6 A. Doubling the current density did not increase the copper concentration in the solution (Figure $2 \mathrm{~b}$ ). The weight of the products on the electrodes was $0.3455 \mathrm{~g}$ when $0.8 \mathrm{~A}$ current was used and increased to $0.6334 \mathrm{~g}$ with $1.6 \mathrm{~A}$ current. Visual observation and weight analysis of the products on the plates and the solution after the tests indicated that high current density increased only the product mass on the electrode surface, not in the solution. This is consistent with the findings of Campagnol et al. [24] which demonstrate that higher current densities will favour deposition of HKUST-1 on the electrode surface [24].

\subsection{Electrosynthesis of HKUST-1}

To prevent passivation of the electrodes and enable continuous electrosynthesis of HKUST-1 the polarity of the electrodes was reversed in controlled frequency. Polarity reversal reduced the build-up of solids on the electrode plates, allowing for longer electrolysis times, but it also affected the composition of the product. Dark black suspensions were formed when the frequency was set to $0.250 \mathrm{~Hz}$ whereas DC experiments generated blue suspensions with a small amount of dark precipitate that settled easily (Figure 3). According to our previous work [15], the dark precipitate was a copper powder that forms when copper ions are reduced on the electrode surface. The copper concentration of the suspension was significantly higher when polarity reversal was used and the solution had a darker colour in general. According to visual inspection and gravimetric analysis, the products mostly formed on the electrode surfaces during the DC process whereas polarity reversal seems appears to suspend these otherwise deposited particles into solution. 


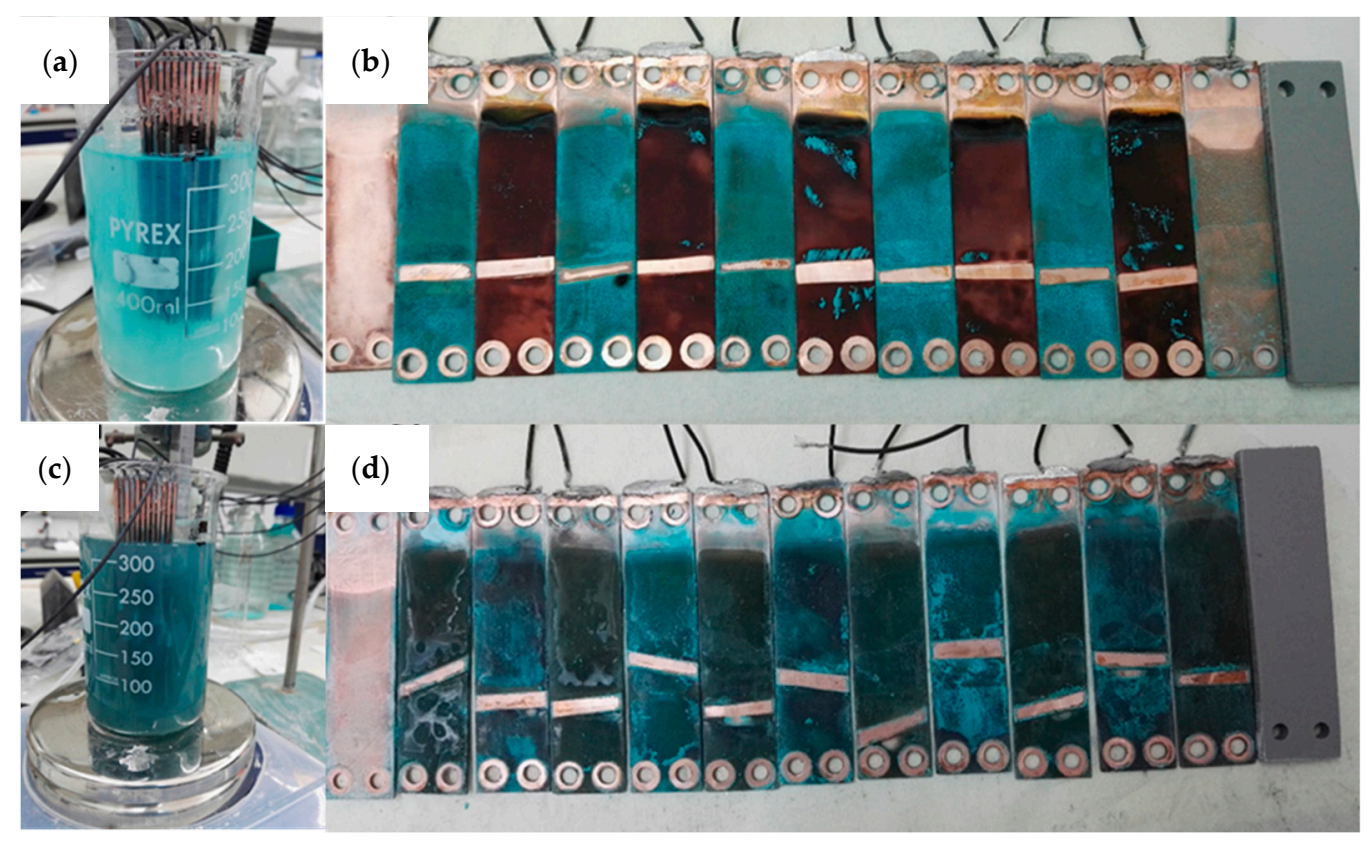

Figure 3. Picture of the test cell and electrodes after synthesis. $(\mathbf{a}, \mathbf{b})$ were used for DC electrosynthesis, whereas $(\mathbf{c}, \mathbf{d})$ used $0.250 \mathrm{~Hz}$ polarity reversal. Strips on electrode surfaces without product deposition are from the use of spacers to control the inter-electrode distances.

The effect of polarity reversal frequency on HKUST-1 yield was studied in the range of $0.05-0.5 \mathrm{~Hz}$ (Figure 4). Cell voltage rapidly increased when $0.050 \mathrm{~Hz}$ and $0.125 \mathrm{~Hz}$ frequencies were used due to the passivation of the electrodes. The lowest cell voltage was measured for the electrosynthesis experiment with $0.250 \mathrm{~Hz}$ frequency. The product yield at low frequencies of $0.050 \mathrm{~Hz}$ and $0.125 \mathrm{~Hz}$ was lower than that of $0.250 \mathrm{~Hz}$ and $0.5 \mathrm{~Hz}$ (Table 1) which is consistent with the cell voltage results and indicates product build-up on the electrode surface. According to the results, low-frequency polarity reversal is not enough to prevent the passive layer build-up on the electrode surface. The highest mass yield in the solution was measured for the $0.250 \mathrm{~Hz}$ polarity reversal frequency. At higher frequencies, the ratio of capacitive current to faradaic current increases, and less copper is released from the electrodes as also shown in our earlier research paper [15].

Table 1. The weight of the products on the electrodes and in the solution after 150 min electrosynthesis time with varying polarity reversal frequencies in $0.078 \mathrm{M} \mathrm{H}_{3} \mathrm{BTC}$ solution with 0.8 A current.

\begin{tabular}{ccc}
\hline Frequency $\mathbf{( H z )}$ & Product on the Electrodes $(\mathrm{g})$ & Product in the Solution $(\mathrm{g})$ \\
\hline 0.050 & 0.7360 & 0.1417 \\
0.125 & 0.5563 & 0.0780 \\
0.250 & 0.3455 & 0.7315 \\
0.500 & 0.4808 & 0.3657 \\
\hline
\end{tabular}


(a)

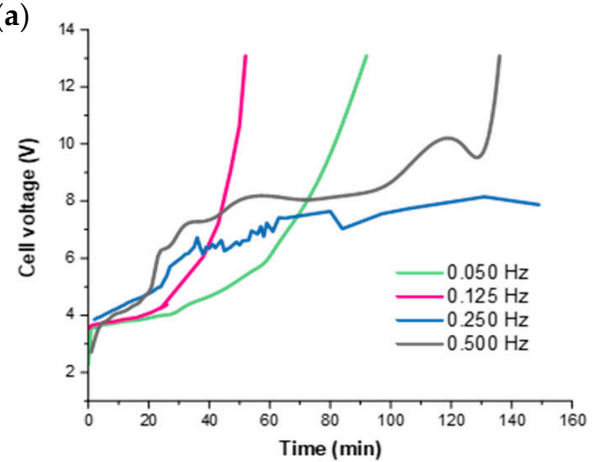

(c)

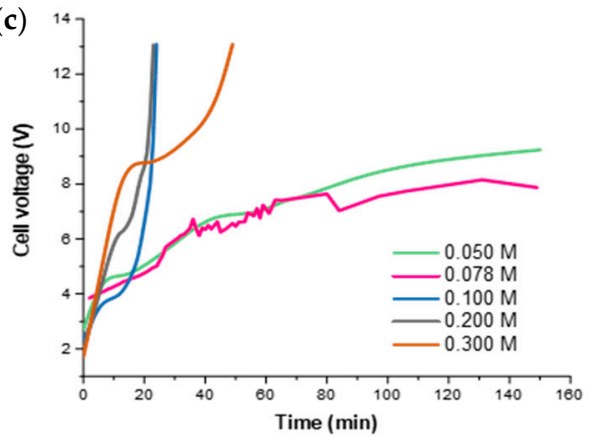

(e)

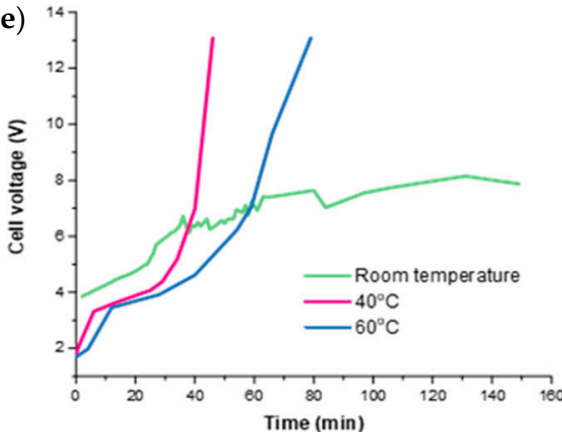

(b)

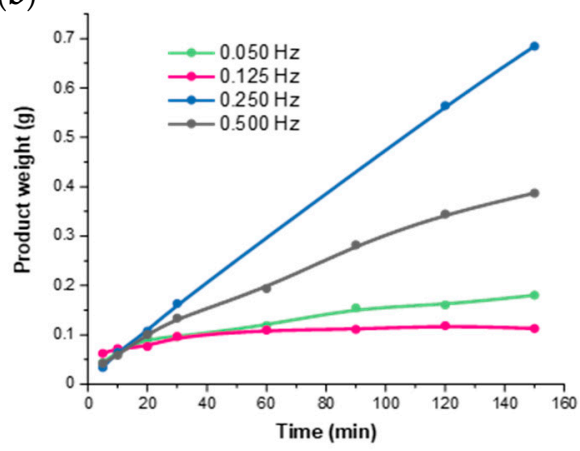

(d)
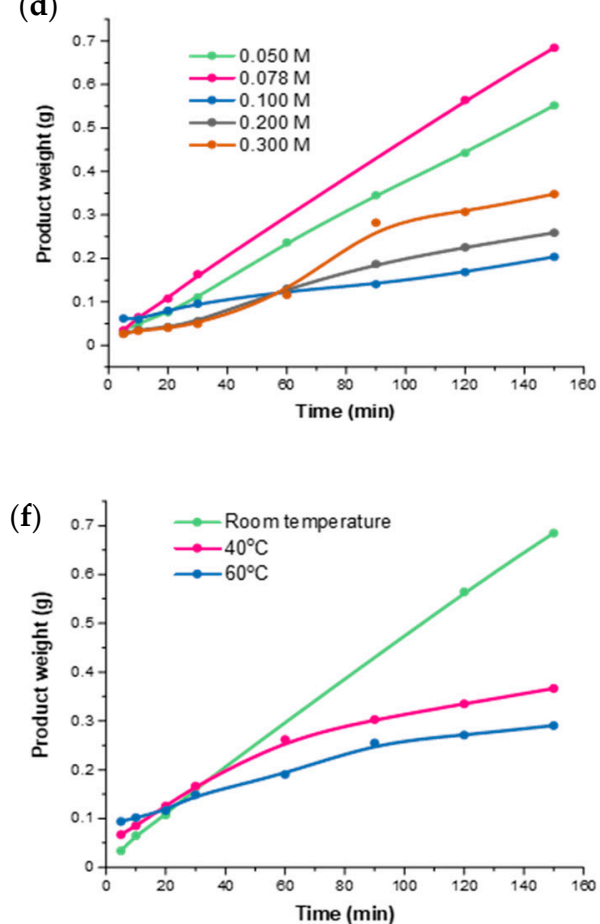

Figure 4 . The cell voltage and product mass of the electrosynthesis at various $(\mathbf{a}, \mathbf{b})$ polarity reversal frequencies, (c,d) $\mathrm{H}_{3} \mathrm{BTC}$ concentrations, and (e,f) synthesis temperatures. The synthesis parameters were $0.078 \mathrm{M} \mathrm{H}_{3} \mathrm{BTC}$ solution, ambient temperature, and $0.250 \mathrm{~Hz}$ polarity reversal frequency except for the parameter that was being studied.

The effect of $\mathrm{H}_{3} \mathrm{BTC}$ concentration on HKUST-1 product quality was studied in the range of $0.01-0.30 \mathrm{M}$. Cell voltage increased rapidly during the electrosynthesis process when the $\mathrm{H}_{3} \mathrm{BTC}$ concentration was $0.1 \mathrm{M}$ or higher (Figure 4) compared to lower concentrations indicating quick passive film formation on the electrode surfaces. The cell voltage reached the recording limit $(13 \mathrm{~V})$ of the system in 0.1-0.3 $\mathrm{M} \mathrm{H}_{3} \mathrm{BTC}$ solutions. According to the gravimetric analysis of the products (Table 2) the lower $\mathrm{H}_{3} \mathrm{BTC}$ concentrations favoured HKUST-1 formation in the solution whereas products grow mostly on the electrode surface in higher concentration solutions. 
Table 2. The weight of the products on the electrodes and in the solution after 150 min electrosynthesis time with varying $\mathrm{H}_{3}$ BTC concentrations using $0.250 \mathrm{~Hz}$ polarity reversal and $0.8 \mathrm{~A}$ current.

\begin{tabular}{ccc}
\hline $\mathbf{H}_{\mathbf{3}} \mathbf{B T C}$ Concentration $(\mathbf{M})$ & Product on the Electrodes $\mathbf{( g )}$ & Product in the Solution $(\mathbf{g})$ \\
\hline 0.050 & 0.5136 & 0.6353 \\
0.078 & 0.3455 & 0.7315 \\
0.100 & 0.5418 & 0.1910 \\
0.200 & 0.4765 & 0.2836 \\
0.300 & 0.6403 & 0.3704 \\
\hline
\end{tabular}

SEM images (Figure 5) demonstrate that crystal morphology is typical of HKUST-1 when the $\mathrm{H}_{3} \mathrm{BTC}$ concentration was between 0.05 and $0.078 \mathrm{M}$. When this concentration was $0.1 \mathrm{M}$ bar-shaped structures were detected, and greater concentrations resulted in fibrous products without any typical HKUST-1 crystal morphologies visible. In the highest $\mathrm{H}_{3}$ BTC concentrations, a white precipitate was formed on the electrode surface. Nitrogen adsorption isotherm results were consistent with the SEM analysis, as increasing the $\mathrm{H}_{3}$ BTC concentration above $0.01 \mathrm{M}$ resulted in products with a lower BET surface area (Table 3). The chemical structure of the fibrous products was not studied in more detail. Van Assche et al. [14] reported similar structures in their research and according to Gascon et al. [25], a one-dimensional coordination polymer $\left[\mathrm{Cu}^{\mathrm{II}}(\mathrm{HBTC})\left(\mathrm{H}_{2} \mathrm{O}\right)_{3}\right]$ is formed when water was used as the solvent instead of an ethanol-water mixture due to partial deprotonation of $\mathrm{H}_{3}$ BTC. Our results show that increasing the $\mathrm{H}_{3} \mathrm{BTC}$ concentration past a certain point will result in the formation of these fibrous products. This may be an effect of $\mathrm{pH}$, as an increased $\mathrm{H}_{3} \mathrm{BTC}$ concentration will result in a more acidic solution where $\mathrm{H}_{3}$ BTC cannot be sufficiently deprotonated for formation of HKUST-1. This idea would be in agreement with previous studies which demonstrate that over-coordinated species can be formed at high $\mathrm{H}_{3}$ BTC concentrations [26].
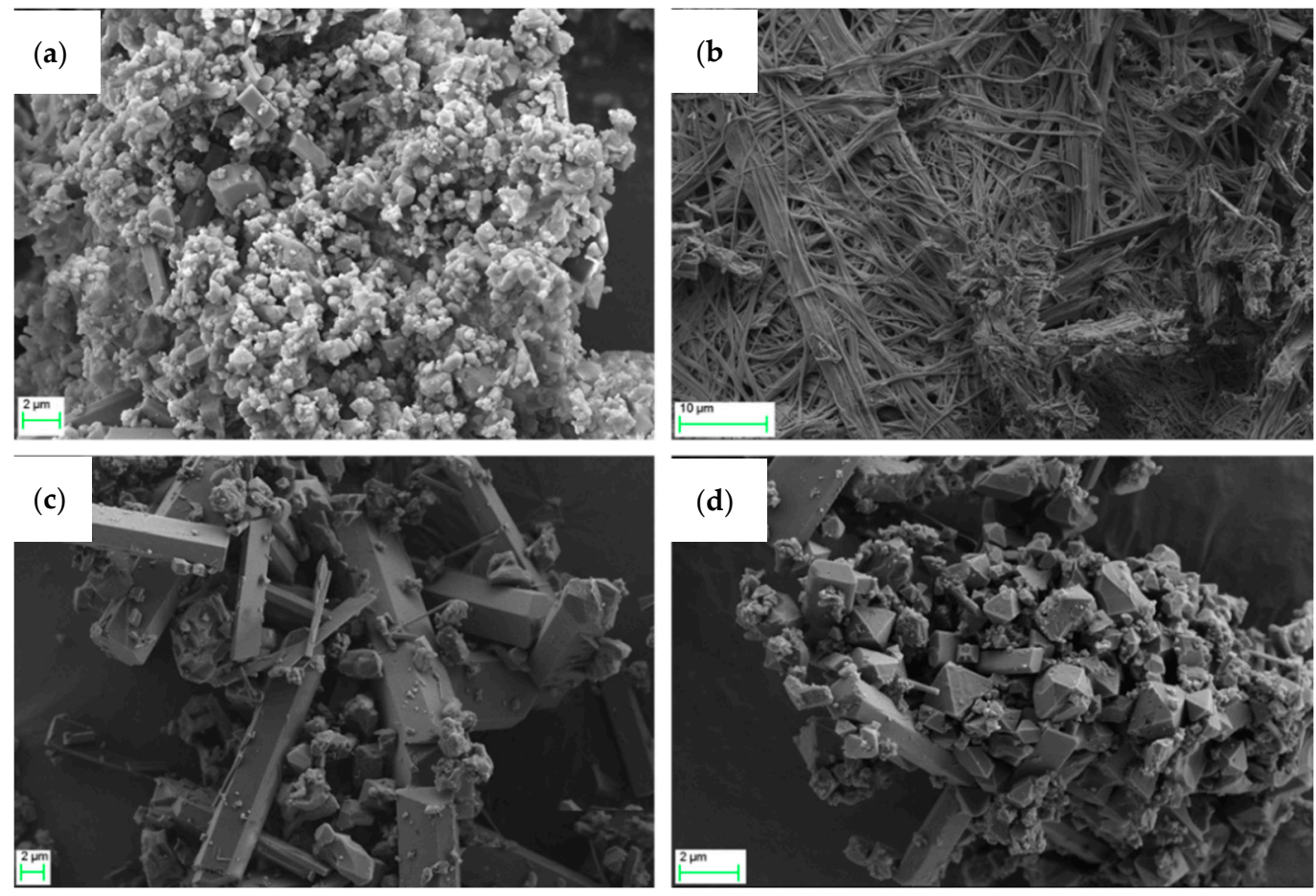

Figure 5. SEM images of the products formed at (a) $0.78 \mathrm{M} \mathrm{H}_{3} \mathrm{BTC}$ solution at room temperature using $0.250 \mathrm{~Hz}$ frequency compared to (b) a higher $\mathrm{H}_{3}$ BTC concentration of $0.300 \mathrm{M}$, (c) a higher temperature of $60{ }^{\circ} \mathrm{C}$, and (d) a lower frequency of $0.05 \mathrm{~Hz}$. 
Table 3. Summary of Brunauer-Emmett-Teller (BET) surface areas for electrosynthesis from $0.01 \mathrm{M}$ to $0.1 \mathrm{M} \mathrm{H}_{3} \mathrm{BTC}$ in batch and using flow processing. Percentage difference calculated as a percentage of batch surface area.

\begin{tabular}{cccc}
\hline $\mathbf{H}_{\mathbf{3}}$ BTC $\mathbf{( M )}$ & Batch SA $\left(\mathbf{m}^{2} / \mathbf{g}\right)$ & Flow Processed SA $\left(\mathbf{m}^{2} / \mathbf{g}\right)$ & \% Difference \\
\hline 0.01 & 1550 & 1716 & 11 \\
0.05 & 892 & 1625 & 82 \\
0.078 & 481 & 1531 & 218 \\
0.1 & 559 & 1292 & 131 \\
\hline
\end{tabular}

The effect of temperature on electrosynthesis was studied at $20^{\circ} \mathrm{C}, 40^{\circ} \mathrm{C}, 60^{\circ} \mathrm{C}$, and $80^{\circ} \mathrm{C}$. An increase in temperature improved the conductivity of the solution and hence reduced the initial cell voltage. However, the cell voltage increased rapidly indicating faster passivation of the electrodes at elevated temperatures compared to the room temperature. Warmer temperatures resulted in lower product yields in the solution. The product formed at $20^{\circ} \mathrm{C}$ consisted of small crystals that had typical HKUST-1 morphology. In contrast, products synthesised at elevated temperatures were less pure, exhibiting small HKUST-1 crystals mixed with larger bar-shaped products.

The optimisation of current density, polarity reversal frequency, $\mathrm{H}_{3} \mathrm{BTC}$ concentration, and temperature are important for efficient batch electrosynthesis of HKUST-1. Results show that there are three major reactions taking place; anodic copper ion release, HKUST-1 formation, and copper ion reduction to the metallic state. Low current density, low $\mathrm{H}_{3} \mathrm{BTC}$ concentration, and low temperature improve the yield of HKUST- 1 and reduce the number of side-products. The optimum polarity reversal frequency is $0.250 \mathrm{~Hz}$. At high frequencies, the proportion of the capacitive current to faradaic current is higher and therefore less copper is released into the solution. Conversely, at lower frequencies, passive layers coat the electrode surfaces, also resulting in lower yields. Lower $\mathrm{H}_{3} \mathrm{BTC}$ concentrations favour HKUST- 1 formation over other products, such as fibrous $\mathrm{Cu}(\mathrm{BTC})\left(\mathrm{H}_{2} \mathrm{O}\right)_{3}$, and ambient temperature reduces the formation of metallic copper precipitates as seen in Figure 5. It is possible that optimisation of other parameters, such as flow speed inside the electrochemical cell, can further improve the yield.

\subsection{Flow-Reactor Postprocessing}

An additional processing step is required to improve the product quality as HKUST-1 produced in the batch process is mixed with impurities. In this work, we combined the electrosynthesis system with a flow reactor to enhance the conversion towards HKUST-1. A set of comparison trials were conducted using $\mathrm{H}_{3} \mathrm{BTC}$ concentrations between $0.01 \mathrm{M}$ and $0.1 \mathrm{M}$, with and without flow reactor post-treatment. The residence time in the flow reactor coils was 6 min at $80^{\circ} \mathrm{C}$. The PXRD pattern of flow processed electrochemically-synthesised product is similar to the HKUST-1 simulated pattern with some variation in peak intensities (Figure 6). 


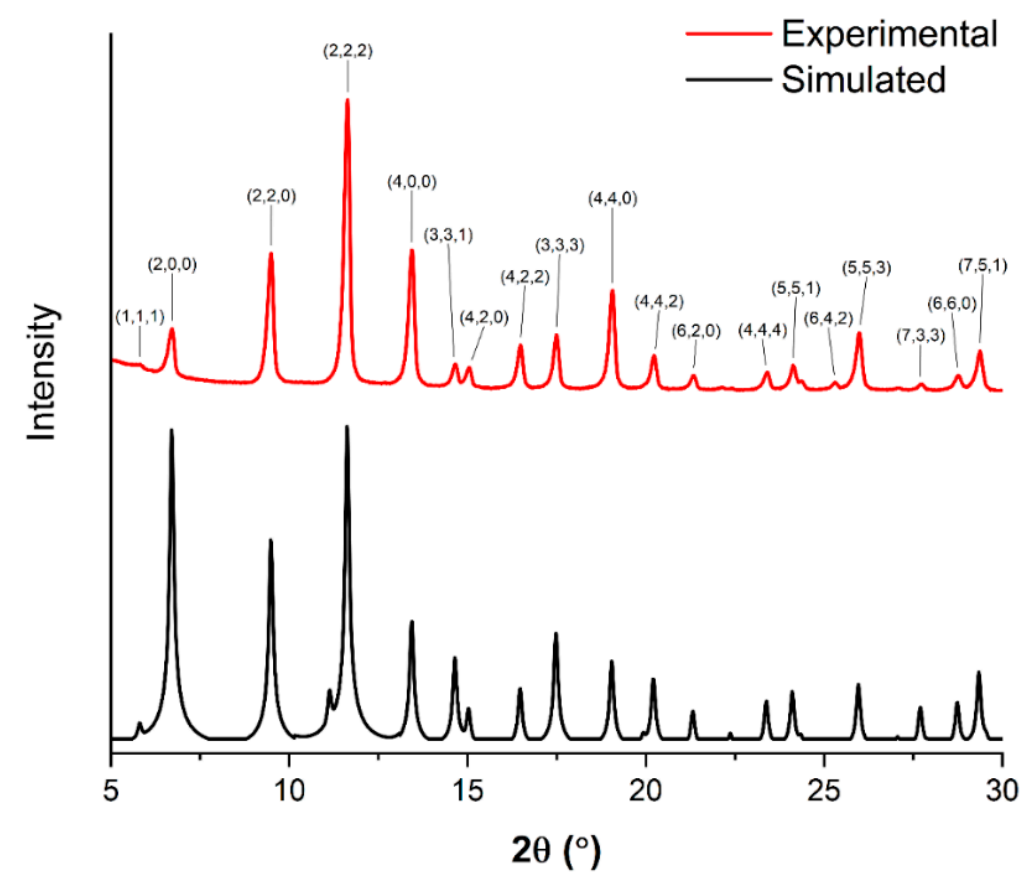

Figure 6. Powder X-ray diffraction (PXRD) pattern of flow processed electrochemically synthesised HKUST-1 using $0.05 \mathrm{M} \mathrm{H}_{3}$ BTC, and a simulated HKUST-1 pattern.

The experimental peak intensities are similar to those demonstrated in our previous work [15], and their deviation from the simulated peak intensities may be explained by the hydration of the sample as HKUST-1 absorbs water from the air [27]. The SEM images demonstrate that electrosynthesis paired with flow processing produced a product with greater purity (Figure 7).
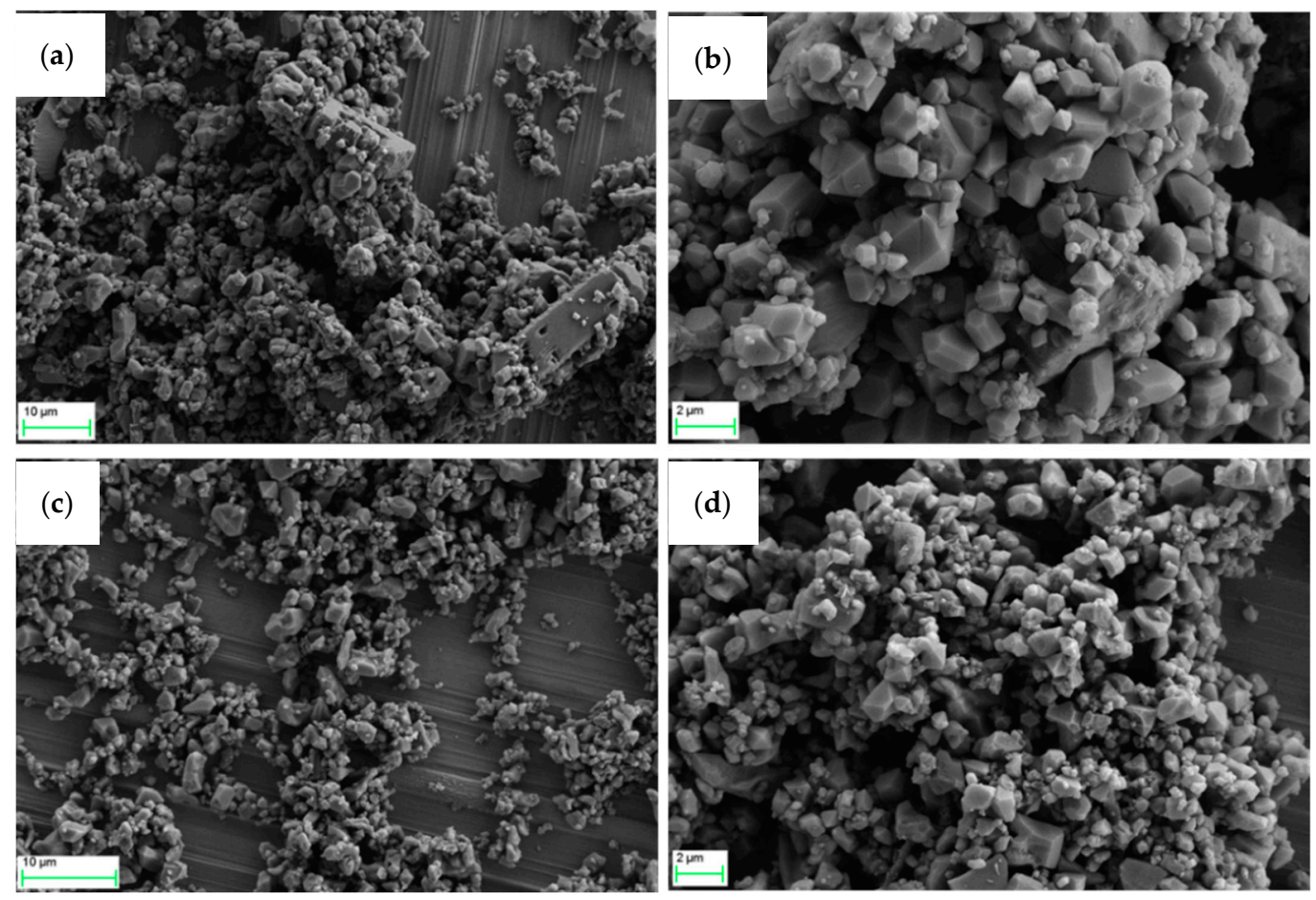

Figure 7. SEM images of the product from batch electrosynthesis $(\mathbf{a}, \mathbf{b})$, and electrosynthesis with flow processing (c,d). Both syntheses used a $\mathrm{H}_{3}$ BTC concentration of $0.05 \mathrm{M}$. 
SEM images of products from batch and flow syntheses both presented crystals with typical morphology of HKUST-1, but the batch products also presented another brickshaped solid phase. Similar impurities were seen in SEM images of all batch products but were more common in experiments using higher concentrations of $\mathrm{H}_{3} \mathrm{BTC}$. Further characterisation of these byproducts has not been pursued, but as these impurities appear to have a similar brightness to HKUST-1 crystals in SEM images they are likely copper-based.

$\mathrm{N}_{2}$ adsorption-desorption isotherms at $77 \mathrm{~K}$ are shown in Figure 8. All products from batch and flow syntheses exhibited a plateau with almost zero $\mathrm{N}_{2}$ adsorption, indicating their non-porous structure. The adsorption equilibriums were quickly reached in the low relative pressure region, and there were no hysteresis loops shown under high relative pressure. This shape indicates that it is a Type I isotherm suggesting microporous $(<2 \mathrm{~nm})$ structure of the samples $[19,28]$.

(a)

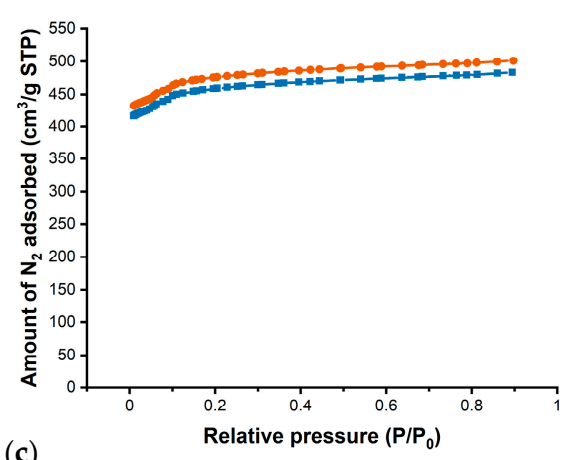

(c)

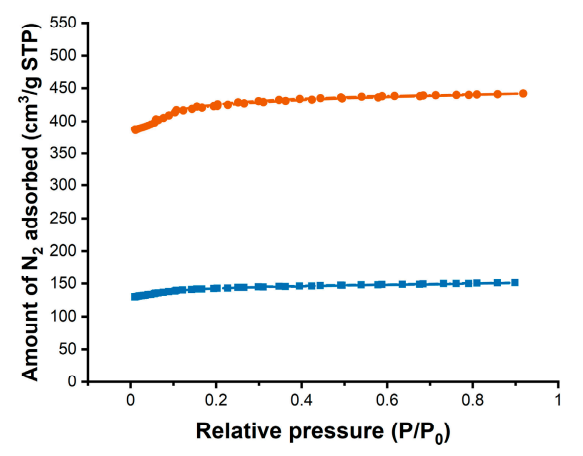

(b)

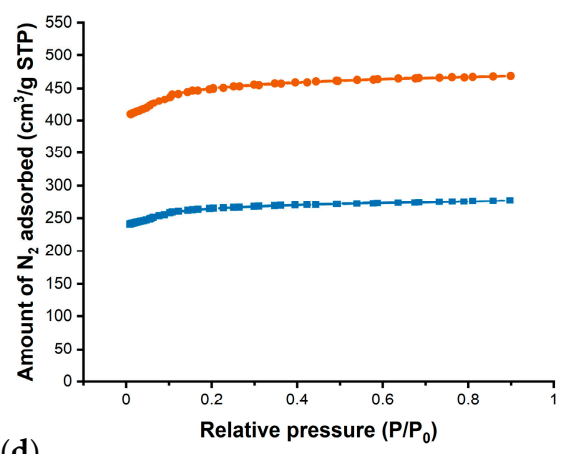

(d)

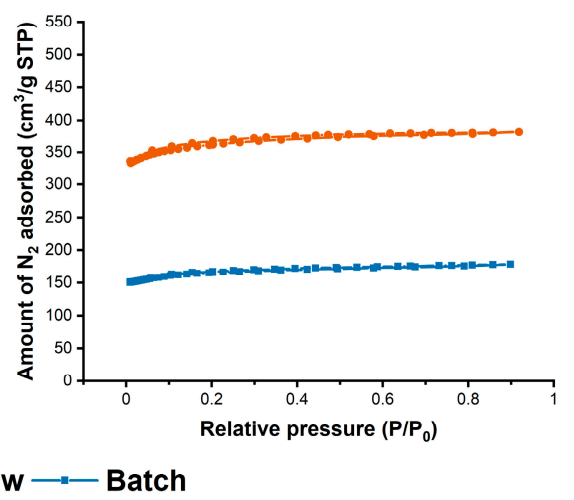

Figure 8. $\mathrm{N}_{2}$ isotherms at $77 \mathrm{~K}$ for flow and batch electrosynthesis of HKUST-1 from (a) $0.01 \mathrm{M}$, (b) $0.05 \mathrm{M}$, (c) $0.078 \mathrm{M}$ and (d) $0.1 \mathrm{M} \mathrm{H}_{3} \mathrm{BTC}$.

Flow processed products also demonstrated improved BET surface areas compared to batch electrosynthesis products (Table 3 ).

At lower $\mathrm{H}_{3} \mathrm{BTC}$ concentrations the difference in surface area between batch and flow electrosynthesis is less as the product is already more pure. Significant differences between batch and flow become more apparent at $\mathrm{H}_{3} \mathrm{BTC}$ concentrations $0.05 \mathrm{M}$ and higher, demonstrating that flow processing is successful in the conversion of undesired byproducts with lower porosity to commercial quality HKUST-1. These results demonstrate that PR electrosynthesis and flow synthesis are complementary techniques with a number of benefits. PR electrosynthesis can produce copper ions without a need for metal salts or additional electrolytes, and any resulting byproducts can be converted to an additional product after processing with the flow reactor. These products required no additional washing and were simply filtered after being collected from the flow reactor.

Further work could investigate this combination in the preparation of other MOFs or focus on optimization, considering electrochemical and flow reactor variables. 


\section{Conclusions}

In this paper, the process parameters of the electrochemical synthesis of HKUST-1 were optimised. Electrochemical HKUST-1 synthesis was combined with flow processing to produce a scalable synthesis method that produces high-quality products without additional electrolyte or washing. Low current density favoured product formation in the solution instead of as a coating on electrode surfaces. Polarity reversal was required to run the electrochemical cell as a continuous process. The optimal parameters for batch synthesis used an $\mathrm{H}_{3} \mathrm{BTC}$ concentration of $0.01 \mathrm{M}, 0.8$ A current at $0.250 \mathrm{~Hz}$, and ambient temperature. Optimised batch electrosynthesis produced a product with a BET surface area of $1550 \mathrm{~m}^{2} / \mathrm{g}$ at optimized conditions, but higher concentrations of $\mathrm{H}_{3}$ BTC resulted in an inferior product. Pairing electrosynthesis with flow processing produced the greatest BET surface areas, allowing for commercial quality HKUST- 1 to be produced over a greater range of $\mathrm{H}_{3} \mathrm{BTC}$ concentrations. These results demonstrate that the pairing of flow processing with electrochemical synthesis provides greater control over process conditions, and that this combination could be valuable in the production of other electrochemically synthesised products.

Author Contributions: Conceptualisation, M.V., D.S.M. and M.R.-M.; methodology, M.V., D.S.M. and M.R.-M.; investigation, H.G. and B.H.; formal analysis, M.V., B.B., D.S.M. and H.G.; data curation, H.G.; resources, M.V. and M.R.-M.; funding acquisition, M.V. and M.R.-M.; supervision, M.R.-M. and M.V.; validation, H.G., B.H., M.V. and D.S.M.; visualisation, B.B., D.S.M. and M.V.; writing—original draft, M.V., D.S.M. and B.B.; writing-review and editing, M.V., D.S.M. and B.B. All authors have read and agreed to the published version of the manuscript.

Funding: This research was funded by CSIRO Mineral Resources.

Institutional Review Board Statement: Not applicable.

Informed Consent Statement: Not applicable.

Acknowledgments: The authors wish to acknowledge Ludmilla Malishev for her assistance in the sample preparations and laboratory analysis.

Conflicts of Interest: The authors declare no conflict of interest.

\section{References}

1. Ghanbari, T.; Abnisa, F.; Daud, W.M.A.W. A review on production of metal organic frameworks (MOF) for $\mathrm{CO}_{2}$ adsorption Sci. Total Environ. 2020, 707, 135090. [CrossRef]

2. Li, J.-R.; Kuppler, R.J.; Zhou, H.-C. Selective gas adsorption and separation in metal-organic frameworks. Chem. Soc. Rev. 2009, 38, 1477-1504. [CrossRef]

3. Silva, P.; Vilela, S.M.F.; Tomé, J.P.C.; Paz, F.A.A. Multifunctional metal-organic frameworks: From academia to industrial applications. Chem. Soc. Rev. 2015, 44, 6774-6803. [CrossRef] [PubMed]

4. Kirchon, A.; Feng, L.; Drake, H.F.; Joseph, E.A.; Zhou, H.-C. From fundamentals to applications: A toolbox for robust and multifunctional MOF materials. Chem. Soc. Rev. 2018, 47, 8611-8638. [CrossRef] [PubMed]

5. Al-Kutubi, H.; Gascon, J.; Sudhölter, E.J.R.; Rassaei, L. Electrosynthesis of Metal-Organic Frameworks: Challenges and Opportunities. ChemElectroChem 2015, 2, 462-474. [CrossRef]

6. Lee, Y.-R.; Kim, J.; Ahn, W.-S. Synthesis of metal-organic frameworks: A mini review. Korean J. Chem. Eng. 2013, 30, 1667-1680. [CrossRef]

7. Varsh, V.M.; Nageswaran, G. Review—Direct Electrochemical Synthesis of Metal Organic Frameworks. J. Electrochem. Soc. 2020, 167, 155527. [CrossRef]

8. Rubio-Martinez, M.; Avci-Camur, C.; Thornton, A.W.; Imaz, I.; Maspoch, D.; Hill, M.R. New synthetic routes towards MOF production at scale. Chem. Soc. Rev. 2017, 46, 3453-3480. [CrossRef]

9. Rubio-Martinez, M.; Hadley, T.D.; Batten, M.P.; Constanti-Carey, K.; Barton, T.; Marley, D.; Mönch, A.; Lim, K.-S.; Hill, M.R. Scalability of Continuous Flow Production of Metal-Organic Frameworks. ChemSusChem 2016, 9, 938-941. [CrossRef] [PubMed]

10. Batten, M.P.; Rubio-Martinez, M.; Hadley, T.; Carey, K.-C.; Lim, K.-S.; Polyzos, A.; Hill, M.R. Continuous flow production of metal-organic frameworks. Curr. Opin. Chem. Eng. 2015, 8, 55-59. [CrossRef]

11. Truckan, N.; Müller, U.; Panchenko, A.; Malkowsky, I.M.; Fischer, A. Novel Metal-Organic Frameworks as Electrode Material for Lithium Ion Accumulators. U.S. Patent WO2011IB51696, 19 April 2011.

12. Kumar, R.S.; Kulandainathan, M.A. Efficient electrosynthesis of highly active $\mathrm{Cu}_{3}(\mathrm{BTC})_{2}$-MOF and its catalytic application to chemical reduction. Microporous Mesoporous Mater. 2013, 168, 57-64. [CrossRef] 
13. Hartmann, M.; Kunz, S.; Himsl, D.; Tangermann, O.; Ernst, S.; Wagener, A. Adsorptive Separation of Isobutene and Isobutane on $\mathrm{Cu}_{3}(\mathrm{BTC})_{2}$. Langmuir 2008, 24, 8634-8642. [CrossRef]

14. Van Assche, T.R.; Desmet, G.; Ameloot, R.; De Vos, D.E.; Terryn, H.; Denayer, J.F. Electrochemical synthesis of thin HKUST-1 layers on copper mesh. Microporous Mesoporous Mater. 2012, 158, 209-213. [CrossRef]

15. Vehrenberg, J.; Vepsäläinen, M.; Macedo, D.S.; Rubio-Martinez, M.; Webster, N.A.; Wessling, M. Steady-state electrochemical synthesis of HKUST-1 with polarity reversal. Microporous Mesoporous Mater. 2020, 303, 110218. [CrossRef]

16. Chui, S.S. A Chemically Functionalizable Nanoporous Material $\left[\mathrm{Cu}_{3}(\mathrm{TMA})_{2}(\mathrm{H} 2 \mathrm{O})_{3}\right]_{\mathrm{n}}$. Science 1999, 283, 1148-1150. [CrossRef]

17. Al-Rowaili, F.N.; Jamal, A.; Shammakh, M.S.B.; Rana, A. A Review on Recent Advances for Electrochemical Reduction of Carbon Dioxide to Methanol Using Metal-Organic Framework (MOF) and Non-MOF Catalysts: Challenges and Future Prospects. ACS Sustain. Chem. Eng. 2018, 6, 15895-15914. [CrossRef]

18. Farrusseng, D.; Aguado, S.; Pinel, C. Metal-Organic Frameworks: Opportunities for Catalysis. Angew. Chem. Int. Ed. 2009, 48, 7502-7513. [CrossRef] [PubMed]

19. Klimakow, M.; Klobes, P.; Thünemann, A.F.; Rademann, K.; Emmerling, F. Mechanochemical Synthesis of Metal-Organic Frameworks: A Fast and Facile Approach toward Quantitative Yields and High Specific Surface Areas. Chem. Mater. 2010, 22, 5216-5221. [CrossRef]

20. Dunne, P.W.; Lester, E.; Walton, R.I. Towards scalable and controlled synthesis of metal-organic framework materials using continuous flow reactors. React. Chem. Eng. 2016, 1, 352-360. [CrossRef]

21. Lafront, A.-M.; Safizadeh, F.; Ghali, E.; Houlachi, G. Study of the copper anode passivation by electrochemical noise analysis using spectral and wavelet transforms. Electrochim. Acta 2010, 55, 2505-2512. [CrossRef]

22. Landolt, D.; MullerR, H.; Tobias, C.W. High Rate Anodic Dissolution of Copper. J. Electrochem. Soc. 1969, 116, 1384-1390. [CrossRef]

23. Joaristi, A.M.; Juan-Alcañiz, J.; Serra-Crespo, P.; Kapteijn, F.; Gascon, J. Electrochemical Synthesis of Some Archetypical Zn ${ }^{2+}$, $\mathrm{Cu}^{2+}$, and $\mathrm{Al}^{3+}$ Metal Organic Frameworks. Cryst. Growth Des. 2012, 12, 3489-3498. [CrossRef]

24. Campagnol, N.; Van Assche, T.R.C.; Li, M.; Stappers, L.; Dincă, M.; Denayer, J.F.M.; Binnemans, K.; De Vos, D.E.; Fransaer, J. On the electrochemical deposition of metal-organic frameworks. J. Mater. Chem. A 2016, 4, 3914-3925. [CrossRef]

25. Gascon, J.; Aguado, S.; Kapteijn, F. Manufacture of dense coatings of $\mathrm{Cu}_{3}(\mathrm{BTC})_{2}$ (HKUST-1) on $\alpha$-alumina. Microporous Mesoporous Mater. 2008, 113, 132-138. [CrossRef]

26. Schäfer, D.P. Electrochemical Growth of CuBTC: Improving the Synthesis Toolkit through Mechanistic Understanding. Ph.D. Thesis, University of Johannes Gutenberg, Mainz, Germany, 2017.

27. Schlichte, K.; Kratzke, T.; Kaskel, S. Improved synthesis, thermal stability and catalytic properties of the metal-organic framework compound $\mathrm{Cu}_{3}(\mathrm{BTC})_{2}$. Microporous Mesoporous Mater. 2004, 73, 81-88. [CrossRef]

28. Majchrzak-Kucęba, I.; Bukalak-Gaik, D. Regeneration performance of metal-organic frameworks. J. Therm. Anal. Calorim. 2016, 125, 1461-1466. [CrossRef] 